Article

\title{
Are Housing Prices Sustainable in 35 Large and Medium-Sized Chinese Cities? A Study Based on the Cheap Talk Game and Dynamic GMM
}

\author{
Jie Wang ${ }^{1, *}$, Biyu Peng ${ }^{1}$, Xiaohua $\mathrm{Xia}^{2}$ and Zhu Ma ${ }^{3}$ \\ 1 School of Economics \& Managements, South China Normal University, Guangzhou 510006, China; \\ pengbiyu@m.scnu.edu.cn \\ 2 School of Applied Economics, Renmin University of China, Beijing 100872, China; xia.email@ruc.edu.cn \\ 3 School of Harbor and Maritime Management, Guangzhou Maritime University, Guangzhou 510725, China; \\ mazhu777@163.com \\ * Correspondence: jiewang@m.scnu.edu.cn
}

Citation: Wang, J.; Peng, B.; Xia, X.;

$\mathrm{Ma}, \mathrm{Z}$. Are Housing Prices

Sustainable in 35 Large and

Medium-Sized Chinese Cities? A

Study Based on the Cheap Talk Game

and Dynamic GMM. Sustainability

2021, 13, 12791. https://doi.org/

$10.3390 /$ su132212791

Academic Editor: Grazia Napoli

Received: 20 October 2021

Accepted: 17 November 2021

Published: 19 November 2021

Publisher's Note: MDPI stays neutral with regard to jurisdictional claims in published maps and institutional affiliations.

Copyright: (c) 2021 by the authors. Licensee MDPI, Basel, Switzerland. This article is an open access article distributed under the terms and conditions of the Creative Commons Attribution (CC BY) license (https:/ / creativecommons.org/licenses/by/ $4.0 /)$.

\begin{abstract}
Focusing on the rapid rise of China's housing prices in recent years, in this paper, we construct a model using the cheap talk game that centers on how information receivers in a market make inferences about the true state of the information based on the cost-free signals they receive and then make decisions based on these inferences, which in turn affect market equilibrium. By constructing a cheap talk game model of house prices, we examine the correlation between market expectations, economic fundamentals, and individual housing purchase decisions. Then, we conduct an empirical analysis using the dynamic GMM method based on the panel data of 35 large and medium-sized cities in China. The analysis reveals that: (1) when the whole of society expects housing prices to rise, housing prices will rise regardless of the true state of economic fundamentals; (2) when information on economic fundamentals is accurate and reliable, home buyers tend to make purchase decisions based on such information, thus maximizing the utility of society as a whole; but when information on economic fundamentals is unreliable, home buyers tend to make purchase decisions according to their own housing price expectations, which is not conducive to the optimization of the utility of society as a whole; (3) the empirical results also reveal that expectations are a non-negligible factor in the rise of housing prices, and the coefficient of expectations exceeds that of each economic fundamental; this demonstrates the investment-driven attribute of the housing market in China. At the same time, economic fundamentals have a definite effect on housing prices, which implies that the rise of housing prices in China is supported by objective conditions.
\end{abstract}

Keywords: housing price; expectation; economic fundamental; cheap talk game; dynamic GMM estimation

\section{Introduction}

In recent years, housing prices have risen significantly across China. At the end of 2019 , the average price of newly built commercial residential housing was CNY $65,516 / \mathrm{m}^{2}$ in Shenzhen, CNY 63,054/ $\mathrm{m}^{2}$ in Beijing, CNY 54,467/ $\mathrm{m}^{2}$ in Shanghai, and CNY 35,726/ $\mathrm{m}^{2}$ in Guangzhou (the lowest among the four first-tier cities in mainland China), according to the State Statistics Bureau of China. The housing prices above are merely average prices in the four cities. In their central areas, housing prices are often above CNY 100,000/ $\mathrm{m}^{2}$. Moreover, housing prices are also very high in other Chinese cities such as Xiamen, Hangzhou, and Nanjing.

What has caused such high housing prices in China? Undeniably, the rise in housing prices in the last decade is also reasonable in some way. For example, housing prices usually rise with economic growth, population increase, and rising inflation [1-3]. However, housing prices in some cities have risen by more than $50 \%$ within a short period [4], far above those which are attributable to the growth in real economic fundamentals (e.g., GDP, 
disposable income of residents, and regional population) in the corresponding period [5]. How much does real demand, which is determined by economic fundamentals, contribute to the rise in housing prices? What has caused such a rapid rise in the prices of commercial residential housing regardless of real economic fundamentals?

Considering that the economic fundamentals indicative of real demand cannot entirely explain the rapid rise in housing prices, we tried to ascertain the reasons for the rise in housing prices from the perspective of expectations. The objective was to identify a reasonable and effective expectation-guiding mechanism for commercial residential housing prices, thus preventing unreasonable expectations from drastically impacting residential housing prices.

The structure of this study, apart from the introduction, is organized as follows. Section 2 reviews the literature that studies house price fluctuations in terms of both expectations and economic fundamentals. Section 3 constructs a cheap talk game model of house prices under the influence of expectations and economic fundamentals. Additionally, a simulation analysis of the house price cheap talk game model is presented. Section 4 empirically tests the effects of both expectations and economic fundamentals on house prices using house price data from 35 large and medium-sized cities in China using a dynamic GMM approach. Finally, Section 5 gives conclusions and suggestions for future research.

\section{Literature Review}

\subsection{Effect of Expectations on Housing Price Fluctuations}

Housing prices are affected by diverse factors. Many researchers have attempted to ascertain the primary cause of rising housing costs from the perspective of price expectations. An annual survey of four U.S. cities shows that the expectations of buyers with regard to the value of housing are well-fitted and correctly anticipate real variation in housing prices [6]. Studies show that the variation in fundamentalists' expectations increase the fluctuation frequency, and the variation in chartists' expectations affect the fluctuation range of housing prices [7]. Scholars distinguish between rational and irrational bubbles in house prices, and point out that rational bubbles occur when these include partial overvaluation caused by the rational expectations of future rental income and capital gains, while irrational bubbles are caused by the irrational behavior of investors and agents that is not captured by the model [8,9]. Some researchers note that people are accustomed to adjusting their expectations based on past experience, so sellers will raise the selling prices of their property if they observe a market increase [10]. A Michigan survey shows that buyers' housing price expectations are closely related to the historical housing prices of the cities in which they reside [11]. Another study shows that even if behavioral biases are controlled for, housing prices are nevertheless closely related to investors' extrapolative expectations [12]. The primary finding is that housing price expectations negatively influence the likelihood of having better subjective well-being (SWB), but only for homeowners without a home loan [13]. Some scholars argue that expectations of future housing prices are arguably an important determinant of actual housing costs, and an important input for decisions on whether and how to transact in the housing market [14].

Research by many scholars has also found that house price expectations are influenced by many other factors in addition to the expectations themselves. Kousky studied the capitalization effect of flood risk on property prices, considering a long set of records for a sample of single-family residential property sales in St. Louis County between 1979 and 2006. The findings suggest that homebuyers are willing to pay more to live in an area with low flood risk [15]. Similarly, Votsis and Perrels investigated the relationship between flood risk disclosure and property prices in three Finnish cities, namely, Helsinki, Pori, and Rovaniemi. They found that the price of property located in floodplains decreased significantly after flood risk disclosure [16]. Hansen, Benson, and Hagen investigated the effect of proximity to a pipeline location on housing values by using a set of housing data from Bellingham, Washington [17]. They confirmed that as long as pipeline explosions are 
not dug up and reported, pipeline locations do not become a public concern and do not pose a potential risk to nearby communities. Intense media coverage is the primary cause of public overreaction. However, this effect wanes over time, which is consistent with other studies on overreaction. Deng, Gan, and Hernandez [18] considered the perceived risk of earthquakes by investigating the relationship between floor and housing value. A unique set of new apartments was used to conduct the study. They found that there was a significant increase in relative housing prices for lower versus higher floors after the May 2008 Wenchuan earthquake. These important findings suggest that overreaction/fear of earthquakes is a short-term behavior that dissipates in the long run. Wong [19] considers the public's reaction to the 2003 Severe Acute Respiratory Syndrome (SARS) epidemic in Hong Kong. Wong's study investigates a large number of housing transaction records, including housing values and number of houses. She found that the market reacted to the SARS epidemic in a surprisingly cautious and rational manner, taking a wait-and-see attitude and not showing an overreaction.

\subsection{Effect of Economic Fundamentals on the Rise in Housing Prices}

Researchers have also investigated the reasons for the fluctuation of housing prices from the perspective of economic fundamentals in addition to expectations. Fair examined the correlation between housing prices and income and rental expectations, arguing that in circumstances of slow variation in short-term housing supply, the rise in housing prices is caused by the two economic fundamentals of income and rental expectations [20]. Researchers have predicted the rise in China's housing prices based on economic fundamentals, arguing that there are no bubbles in China's property market [21]. On the one hand, some scholars argue that during the great moderation period, housing prices were closely related to fund flows [22]. On the other hand, some scholars believe that the global rise in land prices since the Second World War is a major cause of the rise in housing costs [23]. Another study investigated whether the use of a single currency increased housing price convergence among various countries; the conclusion of the study seems to be that there is some influence [24]. At the same time, estimates from panel VAR models for 22 emerging market economies (EMEs) provide evidence of the significant impact of bank credit on the value of housing [25]. Generally speaking, scholars agree that population and GDP are the most important factors for predicting housing prices [26]. If macroeconomic variables and government intervention are controlled, housing prices converge toward fundamental values [27]. However, some studies have also found inconsistencies; empirical data from Malaysia also show that housing supply and housing prices are non-linearly related [28]. Scholars creatively studied the housing needs of Generation X and Generation $\mathrm{Y}$ in Hong Kong. The results of the interviews conducted show that both Generation $\mathrm{X}$ and Generation $Y$ consider price to be the most important factor, and that more individuals from Generation $Y$ rely on government assistance. The questionnaire results found that "income and house price" and "affordability and accessibility" are the most important factors among Generation X and Y, respectively [29].

On the other hand, scholars have also begun to explore other factors that affect house prices besides these common economic fundamentals; these factors include energy, environment, and climate. By employing a combination of approaches to estimate the causal relationship between house prices and energy performance certificates, scholars ${ }^{\prime}$ research support the hypothesis that the energy performance certificate should be more capitalized into house prices in the northern and colder parts of Sweden [30]. Using Hong Kong as an example, scholars examined the correlation between wind direction and the price of fenced buildings built near landfills. Their findings surprisingly reflected an increase in complaints from Tseung Kwan $\mathrm{O}$ residents when more municipal solid waste was sent to landfills in the southeast New Territories. However, overall property prices in the area also increased, which disproved their hypothesis. Innovatively using big data analysis methods, they believe this strange phenomenon can be explained as an "advertising effect". That is, people became aware of the property, visited the site, 
and found that only specific units facing a particular direction were affected. They then purchased the units that were not affected by the foul-smelling wind, leading to an overall increase in property prices [31]. Cho et al. [32] used water quality to examine how water quality deficiencies affect house prices. They demonstrated that homeowners should consider water quality in the presence of standard water quality regulations because water quality deficiencies can affect house prices. Noise is also a factor that affects the price of housing. In Naples, Paola and Guidice found that a $1 \mathrm{~dB}$ increase in noise level resulted in the depreciation of the property value, ranging from $0.30 \%$ to $0.33 \%$ [33]. In addition, scholars have considered the effect of traffic noise generated by roads on housing prices [34], using a dataset that included price, property type, neighborhood, accessibility, noise, and other variables. It was concluded that there are variables for discounts, as well as a disproportionate increase in discounts. Walkability, which describes the extent to which a neighborhood environment is walking-friendly, has recently been regarded as a potential impetus for inflated housing prices [35]. Researchers examined the relationship between the level of walkability and housing prices in Seoul, Korea and found that housing prices positively correlated with the walkability score in areas with low housing prices, whereas no significant association was observed in areas with high housing prices. The results also support public policy proposals relevant to urban planning, environmental design, and housing policies [36]. A paper aimed to estimate and deconstruct the spatial and temporal effects of a flood event that occurred in the city of Laval in 1998 using a hedonic pricing model (HPM) based on a difference-in-differences (DID) estimator. The researchers found that the flooded area needs to be precisely identified to be able to correctly estimate the impact of flood on houses that have faced this phenomenon [37].

\section{Cheap Talk Model for Housing Prices}

As a frontier in game theory, the cheap talk game has received much attention from academia both in China and abroad, and has been extended theoretically [38-40]. However, it has hardly been used to explain the fluctuation of housing prices. This study thus made a preliminary attempt in this regard.

\subsection{Individual and Social Utility of Housing Purchase Decisions}

Based on Crawford and Sobel's game structure and game timing settings for the cheap talk game [38], we then establish the specifics of the house price cheap talk game and assume that there are continuous housing buyers who are evenly distributed between 0 and 1. A buyer selects a strategy, and the utility function of the buyer can be expressed as follows:

$$
u_{i}(a, \theta) \equiv-(1-r)\left(a_{i}-\theta\right)^{2}-r\left(L_{i}-\bar{L}\right), L_{i} \equiv \int_{0}^{1}\left(a_{j}-a_{i}\right)^{2} d j, \bar{L} \equiv \int_{0}^{1} L_{j} d j
$$

In Equation (1), $a_{i}$ denotes the action of the buyer, $\theta$ denotes an economic fundamental, and $r$ denotes the weight of influence of the buyer's behavioral deviation on utility.

The utility loss of the buyer's behavioral deviation comprises two parts: First, the first half of Equation (1) denotes the utility loss arising from the buyer's behavioral deviation from economic fundamentals; second, the second half of Equation (1) denotes the utility loss arising from the buyer's behavioral deviation from the whole society. The $r$ settings show that the correctness of the decisions of buyer $i$ depends on two factors: Firstly, whether the decisions are consistent with social economics; secondly, whether the decisions are consistent with the whole society. The decisions of buyers $i$ may not be consistent with economic fundamentals. If the whole of society expects housing prices to rise, the behavior of buyer $i$ in chasing housing prices will be accepted by others; therefore, individual $i$ can resell the property at a high price. This also implies that due to the expectation effect, housing prices rise against economic fundamentals. Undoubtedly, whether correct or not, the "second guess" behavior of buyer $i$ is ineffective from the perspective of maximized 
overall social utility. In this zero-sum multilateral game, the gain of the winner is equal to the loss of the loser.

According to the utility function above, the optimal action $a_{i}^{*}$ of buyer $i$ can be determined by calculating the derivative of the utility function:

$$
a_{i}^{*}=(1-r) E_{i}(\theta)+r E_{i}(\bar{a})
$$

According to Equation (2), the optimal decision of buyer $i$ depends on his/her expectations of economic fundamentals $E_{i}(\theta)$ and his/her expectations with regard to others' purchase decisions $E_{i}(\bar{a})$.

Overall, social utility $W(a, \theta)$ can be expressed as the mean of standardized individual utility, as follows:

$$
W(a, \theta)=\frac{1}{1-r} \int_{0}^{1} u_{i}(a, \theta) d i=-\int_{0}^{1}\left(a_{i}-\theta\right)^{2} d i
$$

When individual utility is maximized, the buyer's optimal decision is correlated with economic fundamentals and overall social decision. By contrast, Equation (3) shows that the buyer's optimal decision is only correlated with economic fundamentals when social utility is maximized. When social utility is maximized, the buyer's optimal decision is as follows:

$$
a_{i}^{W^{*}}=\theta
$$

Equation (4) shows that an individual's purchase decision should be consistent with economic fundamentals when social utility is maximized.

In summary, this study presents the following propositions.

Proposition 1. The housing purchase decision under optimal social utility is different from that under optimal individual utility. The housing purchase decision under optimal individual utility is correlated with economic fundamentals and expectations on the housing purchase decisions of others, whereas the housing purchase decision under optimal social utility only correlates with economic fundamentals. Decision-making behaviors under optimal individual utility will cause a loss in overall social utility.

\subsection{Expectations on Economic Fundamentals}

We assume that in the game above, the natural information of buyer $i$ comprises two parts: First, public information $y$, namely, information on economic fundamentals, e.g., disposable income of residents, fiscal expenditure, and loan interest rate; second, individual information $x_{i}$, e.g., individual expectations of future housing prices.

Public information is open to the public and contains a deviation due to noises, so public information $y$ can be set as follows:

$$
y=\theta+\eta
$$

where $\theta$ denotes an economic fundamental, and $\eta$ denotes the deviation in public information, $\eta \sim N\left(0, \sigma_{\eta}^{2}\right)$.

Individual information is affected by economic fundamentals and individual characteristics, so the individual information $x_{i}$ of buyer $i$ is structurally set as follows:

$$
x_{i}=\theta+\varepsilon_{i}
$$

where $\theta$ denotes an economic fundamental, and $\varepsilon_{i}$ denotes the deviation in individual information, $\varepsilon_{i} \sim\left(0, \sigma_{\varepsilon_{i}}^{2}\right)$. 
$\alpha$ and $\beta$ respectively denote the accuracy of public information $y$ and individual information $x_{i}$, then:

$$
\begin{aligned}
& \alpha=1 / \sigma_{\eta}^{2} \\
& \beta=1 / \sigma_{\varepsilon_{i}}^{2}
\end{aligned}
$$

Based on observed public and personal information, the individual buyer expects the economic fundamental $\theta$ to be as follows:

$$
E_{i}(\theta)=\frac{\alpha y+\beta x_{i}}{\alpha+\beta}
$$

According to Equation (9), $\alpha>0$ and $\beta>0$, so $\partial E_{i}(\theta) / \partial y>0$. Therefore, we present the following proposition:

Proposition 2. Although there is a deviation in the public information acquired by an individual buyer, his/her expectations of economic fundamentals based on such public information is positively correlated with real economic fundamentals.

\subsection{Equilibrium Analysis of Individual Housing Purchase Decisions}

We assume that an individual buyer makes a housing purchase decision based on individual and public information. Then, the decision function $a_{j}$ of buyer $j$ can be expressed as follows:

$$
a_{j}=\kappa x_{j}+(1-\kappa) y
$$

where $x_{j}$ denotes individual information, $y$ denotes public information, and $\kappa$ denotes the information decision coefficient.

According to Equation (10), the expectations of buyer $i$ with regard to the general housing buyers' decision function can be expressed as follows:

$$
E_{i}(\bar{a})=\kappa E\left(x_{j} \mid y, x_{i}\right)+(1-\kappa) E\left(y \mid y, x_{i}\right)=\left(\frac{\kappa \beta}{\alpha+\beta}\right) x_{i}+\left(1-\frac{\kappa \beta}{\alpha+\beta}\right) y
$$

Substituting Equations (9) and (11) into Equation (2) leads to the optimal decision function of buyer $i$ as follows:

$$
a_{i}^{*}=(1-r) E_{i}(\theta)+r E_{i}(\bar{a})=\left(\frac{\beta(r \kappa+1-r)}{\alpha+\beta}\right) x_{i}+\left(1-\frac{\beta(r \kappa+1-r)}{\alpha+\beta}\right) y
$$

Making a comparison between the coefficients in Equations (10) and (12), we obtain the following equation through substitution:

$$
\kappa=\frac{\beta(1-r)}{\beta(1-r)+\alpha}
$$

By substituting Equation (13) into Equation (12), we obtain the decision function of buyer $i$ below:

$$
a_{i}^{*}=\frac{\alpha y+\beta(1-r) x_{i}}{\alpha+\beta(1-r)}
$$

From Equation (14), we obtain the following equations:

$$
\begin{aligned}
\frac{\partial \alpha_{i}^{*}}{\partial y} & =\frac{\alpha}{\alpha+\beta(1-r)} \\
\frac{\partial \alpha_{i}^{*}}{\partial x_{i}} & =\frac{\beta(1-r)}{\alpha+\beta(1-r)}
\end{aligned}
$$


When $\alpha$ is close to infinity or $\beta$ is close to zero, the following equation is obtained:

$$
\alpha_{i}^{*}=y
$$

When $\alpha$ is close to zero or $\beta$ is close to infinity, the following equation is obtained:

$$
\alpha_{i}^{*}=x_{i}
$$

Thus, the next proposition is:

Proposition 3. When the disclosed information on economic fundamentals is very accurate and reliable, the individual housing purchase decision is consistent with economic fundamentals, thus optimizing overall social utility; when the disclosed information on economic fundamentals is not accurate enough, the individual housing purchase decision is significantly affected by individual information, thus reducing overall social utility.

\subsection{Simulation Analysis of the Cheap Talk Model for Housing Prices}

To verify the conclusions of the game models demonstrated above, we conducted a simulation analysis. According to model assumptions, the exogenous parameters are assigned the following values, $\varepsilon_{i} \sim N(0,7), \varepsilon_{i} \sim N(0,7), \theta=100, \alpha=1 / \sigma_{\eta}^{2}$, and $\beta=1 / \sigma_{\varepsilon_{i}}^{2}$. The assigned values are described as follows: (1) $\eta \sim N(0,1)$ : Notwithstanding the large deviations, public information internally involves numerous individuals and both positive and negative deviations, thus suppressing some fluctuations; therefore, population variance is small, and the mean value is zero; (2) $\varepsilon_{i} \sim N(0,7)$ : Similar to public information, individual information also fluctuates, and there are no counteractive fluctuations within the crowds; therefore, the variance of individual information is larger than that of public information; (3) To simplify the calculation process, the economic fundamental $\theta$ is standardized as $100 ;(4)$ the accuracy of public and individual information $(\alpha, \beta)$ are set to $\alpha=1 / \sigma_{\eta}^{2}, \beta=1 / \sigma_{\varepsilon_{i}}^{2}$, respectively, according to the assumptions above. Based on the abovementioned parameter settings, we can determine the housing purchase decisions under optimal individual and social utility, respectively (as described in Table 1).

The data in the last column of Table 1 show that all the housing purchase decisions under optimal individual utility $a_{i}^{*}$ deviate from those under optimal social utility $a_{i}^{W^{*}}$ in the second to the last column, and $13 a_{i}^{*}$ values exceed the economic fundamental $\theta$. This proves Proposition 1 to be true, that housing purchase decisions under optimal social utility are different from those under optimal individual utility. When the whole of society expects housing prices to rise, housing prices will rise against economic fundamentals, resulting in a loss of social utility.

The data in the third to the last column of Table 1 show that large information deviations (particularly large deviations in individual information) cause definite deviations of public and individual information from economic fundamentals. As a result, individual expectations of economic fundamentals are also different from the real status of economic fundamentals. This also proves Proposition 2 to be true.

To further verify Proposition 2, a graphic simulation was conducted (as shown in Figure 1). According to Proposition 2, individual expectations of economic fundamentals are significantly positively correlated with public information $y$ and individual information $x_{i}$.

The contour maps in Figure 2 also reveal the positive correlation between public and individual information and expectations, in which the horizontal axis represents individual information $x_{i}$ and the longitudinal axis represents public information $y$. The lighter the image, the higher the expectations $E \theta$. 
Table 1. Cheap talk model under optimal individual and social utility.

\begin{tabular}{|c|c|c|c|c|c|c|c|c|}
\hline & $\begin{array}{c}\text { Deviation } \\
\text { in Public } \\
\text { Informa- } \\
\text { tion }\end{array}$ & $\begin{array}{l}\text { Deviation } \\
\text { in } \\
\text { Individual } \\
\text { Informa- } \\
\text { tion }\end{array}$ & $\begin{array}{l}\text { Public In- } \\
\text { formation }\end{array}$ & $\begin{array}{l}\text { Individual } \\
\text { Informa- } \\
\text { tion }\end{array}$ & $\begin{array}{l}\text { Economic } \\
\text { Fundamen- } \\
\text { tals }\end{array}$ & $\begin{array}{c}\text { Expectations } \\
\text { of } \\
\text { Economic } \\
\text { Fundamen- } \\
\text { tals }\end{array}$ & $\begin{array}{l}\text { Purchase } \\
\text { Decision } \\
\text { under } \\
\text { Optimal } \\
\text { Social } \\
\text { Utility }\end{array}$ & $\begin{array}{c}\text { Purchase } \\
\text { Decision } \\
\text { under } \\
\text { Optimal } \\
\text { Individual } \\
\text { Utility }\end{array}$ \\
\hline & $\eta$ & $\varepsilon_{i}$ & $y$ & $x_{i}$ & $\theta$ & $E_{i}(\theta)$ & $a_{i}^{W^{*}}$ & $a_{i}^{*}$ \\
\hline 1 & -0.46 & 0.41 & 99.54 & 100.41 & 100.00 & 99.65 & 100.00 & 99.55 \\
\hline 2 & 1.40 & 9.73 & 101.40 & 109.73 & 100.00 & 102.44 & 100.00 & 101.52 \\
\hline 3 & 0.59 & -10.26 & 100.59 & 89.74 & 100.00 & 99.24 & 100.00 & 100.44 \\
\hline 4 & -1.49 & 12.58 & 98.51 & 112.58 & 100.00 & 100.27 & 100.00 & 98.71 \\
\hline 5 & 0.55 & -11.64 & 100.55 & 88.36 & 100.00 & 99.02 & 100.00 & 100.38 \\
\hline 6 & 0.03 & -1.95 & 100.03 & 98.05 & 100.00 & 99.78 & 100.00 & 100.00 \\
\hline 7 & 1.01 & -2.98 & 101.01 & 97.02 & 100.00 & 100.51 & 100.00 & 100.95 \\
\hline 8 & 2.19 & 1.85 & 102.19 & 101.85 & 100.00 & 102.15 & 100.00 & 102.19 \\
\hline 9 & 1.19 & 7.61 & 101.19 & 107.61 & 100.00 & 101.99 & 100.00 & 101.28 \\
\hline 10 & -0.06 & 16.04 & 99.95 & 116.04 & 100.00 & 101.96 & 100.00 & 100.17 \\
\hline 11 & 0.18 & 12.05 & 100.18 & 112.05 & 100.00 & 101.67 & 100.00 & 100.35 \\
\hline 12 & -0.27 & 2.10 & 99.73 & 102.10 & 100.00 & 100.03 & 100.00 & 99.76 \\
\hline 13 & -0.98 & 4.59 & 99.02 & 104.59 & 100.00 & 99.71 & 100.00 & 99.09 \\
\hline 14 & 1.21 & -10.88 & 101.21 & 89.12 & 100.00 & 99.70 & 100.00 & 101.04 \\
\hline 15 & -1.07 & 4.61 & 98.93 & 104.61 & 100.00 & 99.64 & 100.00 & 99.01 \\
\hline 16 & -0.79 & -10.65 & 99.21 & 89.35 & 100.00 & 97.98 & 100.00 & 99.07 \\
\hline 17 & 0.21 & 6.34 & 100.21 & 106.34 & 100.00 & 100.97 & 100.00 & 100.29 \\
\hline 18 & -0.37 & -12.59 & 99.64 & 87.41 & 100.00 & 98.11 & 100.00 & 99.46 \\
\hline 19 & 1.65 & -12.43 & 101.65 & 87.57 & 100.00 & 99.89 & 100.00 & 101.45 \\
\hline 20 & 0.99 & -7.36 & 100.99 & 92.64 & 100.00 & 99.95 & 100.00 & 100.88 \\
\hline
\end{tabular}
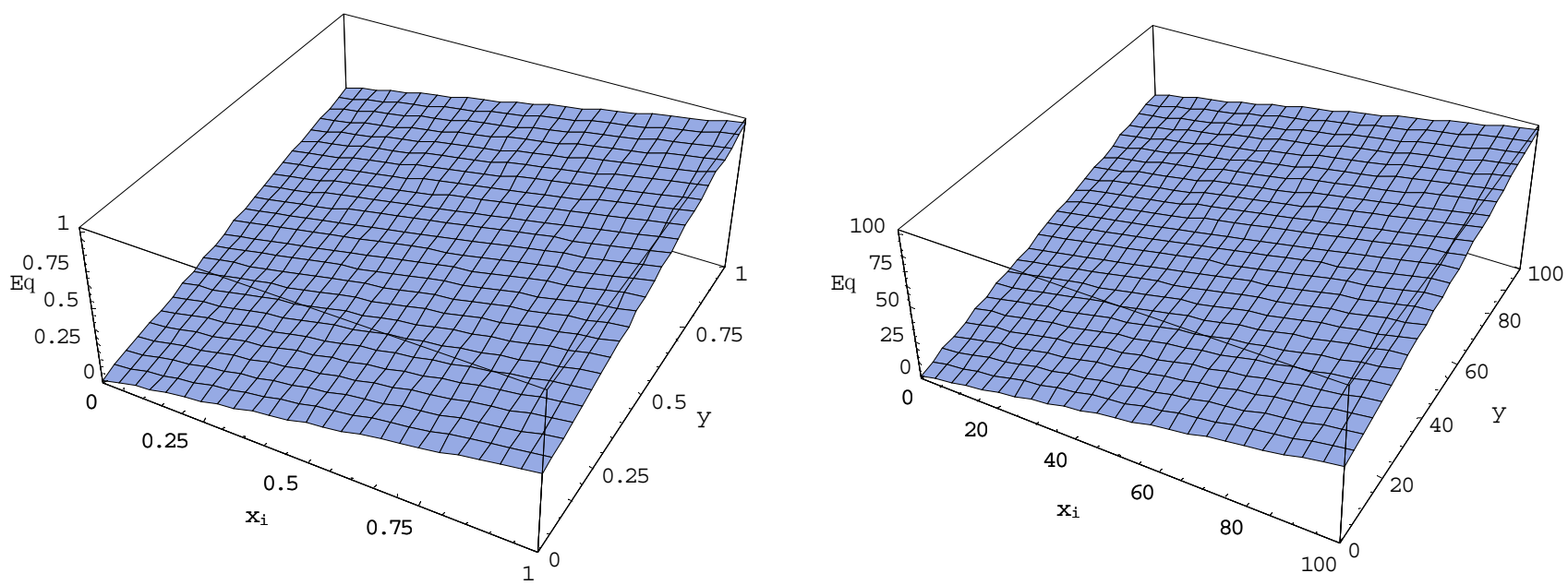

Figure 1. Correlation between individual expectations of economic fundamentals and information. 

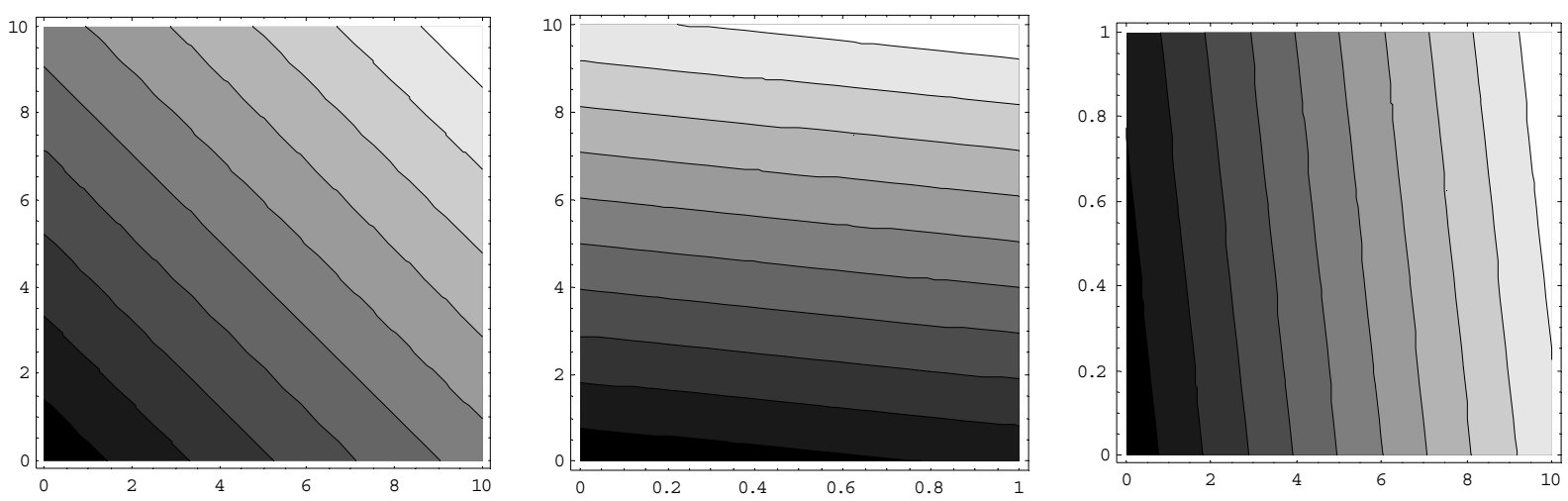

Figure 2. Contour map for individual expectations of economic fundamentals and information.

Unlike the significant effect of individual and public information on expectations, Figure 3 shows that information accuracy does not affect expectations significantly. When information accuracy $\alpha, \beta$ increase respectively, individual expectations of economic fundamentals do not vary significantly, but are always consistent with real economic fundamentals.
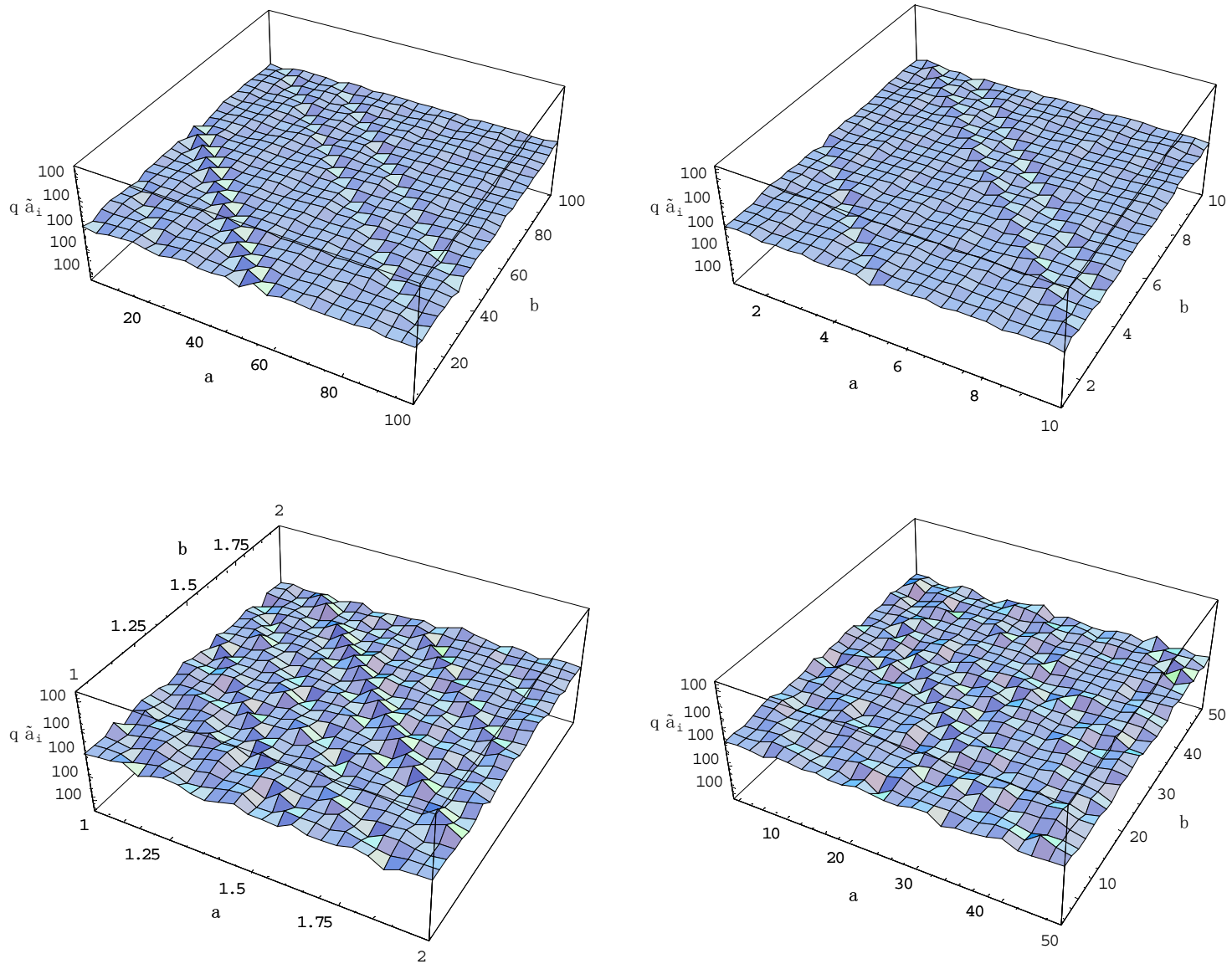

Figure 3. Correlation between individual expectations of economic fundamentals and information accuracy, $\alpha(1,100), \beta(1,100)$.

To verify Proposition 3, Figure 4 simulates the social utility of a housing purchase decision under different parameter environments. When $\alpha$ is close to infinity or $\beta$ is close to zero, the individual housing purchase decision tends to be consistent with public information on economic fundamentals; in this case, the loss of social utility is reduced. Therefore, we can see that the negative values in the vertical axis on the left panel of Figure 4 are very small. The right panel of Figure 4 simulates the situation where public 
information is not accurate but individual information is. The individual housing purchase decision tends to be consistent with individual information but obviously deviates from economic fundamentals; therefore, the loss of social utility is very severe.
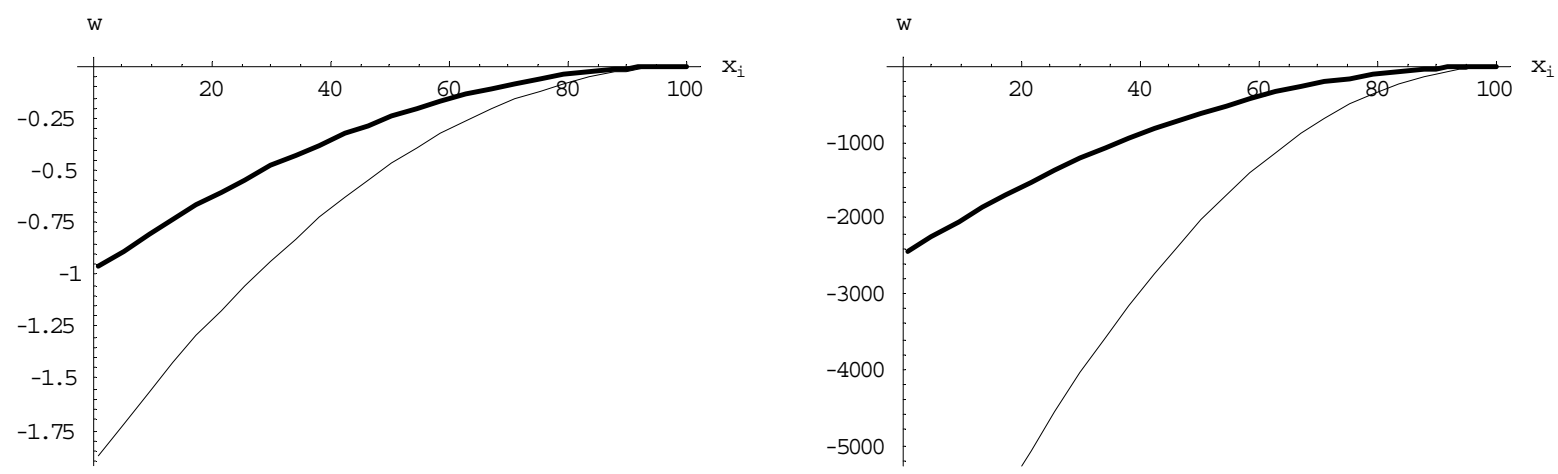

Figure 4. Comparison of the social utility of purchase decisions under different parameter environments.

Figure 4 also shows the significant effect of information accuracy on the social utility of the housing purchase decision. With the relatively high accuracy of public information, the loss of social utility under $\alpha=1.4$ (indicated by the thick line on the left) is approximately $50 \%$ lower than that under $\alpha=1$ (indicated by the thin line), while other parameters are unchanged. With the relatively high accuracy of individual information, the loss of social utility under $\beta=10$ (indicated by the thin line on the right) is higher than that under $\beta=1$ (indicated by the thick line), while other parameters remain unchanged. This further proves Proposition 3 to be true.

\section{Empirical Quantitative Analysis}

In Section 3, we analyzed the effects of expectations and economic fundamentals on housing prices using cheap talk models and the simulation method. We also tested the effect based on empirical data from China.

\subsection{Settings of Measuring Models}

Based on the GMM estimation method [41-46], drawing on the experience of variable selection from the relevant literature $[20-23,26,27,47,48]$, and considering the effect of expectations and economic fundamentals on housing prices and the sales volume, the following models are built:

$$
\begin{gathered}
\ln h p_{i t}=\alpha_{0}+\alpha_{1} \ln E_{i t}+\alpha_{2} \sum \ln Z_{i t}+\eta_{i}+\mu_{i t} \\
\ln h q_{i t}=\beta_{0}+\beta_{1} \ln I_{i t}+\beta_{2} \sum \ln Z_{i t}+\eta_{i}+\mu_{i t} \\
\ln h p_{i t}=\gamma_{0}+\gamma_{1} \ln E_{i t}+\gamma_{2} \ln I_{i t}+\gamma_{3} \sum \ln Z_{i t}+\eta_{i}+\mu_{i t}
\end{gathered}
$$

In the equations, $h p_{i t}$ denotes the housing prices in city $i$ at moment $t ; h q_{i t}$ denotes the housing sales volume in city $i$ at moment $t$; the vector $E_{i t}$ denotes the expectations of housing prices in city $i$ at moment $t$, including adaptive expectation $e s_{i t}$ and rational expectations $e r_{i t}$; the vector $I_{i t}$ denotes the expectations of the housing sales volume in city $i$ at moment $t$, including adaptive expectations $i s_{i t}$ and rational expectations $i r_{i t}$; the vector $Z_{i t}$ denotes an economic fundamental indicative of real housing demand, such as per capita GDP, urban population, per capita disposable income, per capita fiscal expenditure, and housing purchase cost; $\eta_{i}$ is a dummy urban variable, denoting unobservable urban characteristics such as geographic location and city level; $\mu_{i t}$ denotes the independent, identically distributed error term. 


\subsection{Data Sources}

The welfare housing allocation system has been implemented in mainland China for more than 40 years. Under this system, housing for urban residents is mainly provided by their departments and enterprises; governments, departments, and enterprises at all levels uniformly carried out housing construction in accordance with the state's capital construction investment plan. A total of $90 \%$ of the funds for housing construction were mainly allocated by the government, and a small amount was self-financed by the departments and enterprises. After the housing was built, it was distributed to employees according to their rank, length of service, age, number of residents, generations, number of family members, availability of housing, and a series of other conditions. In June 1998, China's State Council decided to stop the practice of allocating welfare housing, and began to implement the monetization of housing allocation. Since then, the real estate market, property transactions, and property prices have emerged in mainland China. To exclude the impact of China's welfare-oriented housing distribution system before 1998, we selected the panel data of 35 large and medium-sized Chinese cities from 2000 to 2014. Drawing on the existing literature on the definition of adaptive and rational expectations [47,48], previous and future housing prices and sales volumes are used as a proxy for adaptive and rational expectations of current housing prices and sales volumes. The study data were cited from China Real Estate Statistics Yearbook, China Economic and Social Development Statistical Database, and China Statistical Yearbook.

\subsection{Data Processing and Descriptive Statistical Analysis of the Sample}

The data of a few indicators/years are missing. In this study, the missing data are filled using the interpolation method. For the value-based data, the effect of inflation is eliminated by using the urban consumer price index of each city. The effect of heteroscedasticity on estimation results is eliminated by using the logarithmic method. Table 2 lists the descriptive analysis results of the processed variables.

Table 2. Description of sample data.

\begin{tabular}{|c|c|c|c|c|c|c|}
\hline Variable & Symbol & Obs & Mean & SD & Min & Max \\
\hline Housing sales price & $h p_{i t}$ & 560 & 4685.73 & 3603.19 & 1077.00 & $24,040.00$ \\
\hline $\begin{array}{l}\text { Adaptive expectations of } \\
\text { housing price }\end{array}$ & $e s_{i t}$ & 560 & 4317.94 & 3259.53 & 1087.61 & $22,811.10$ \\
\hline $\begin{array}{l}\text { Rational expectations of } \\
\text { housing price }\end{array}$ & $e r_{i t}$ & 560 & 4743.48 & 3536.96 & 1113.75 & $23,568.63$ \\
\hline $\begin{array}{l}\text { Housing sales volume } \\
\qquad\left(\text { million } \mathrm{m}^{2}\right)\end{array}$ & $h q_{i t}$ & 560 & 760.34 & 762.11 & 23.61 & 5100.40 \\
\hline $\begin{array}{l}\text { Adaptive expectations of } \\
\text { housing sales volume }\end{array}$ & $i s_{i t}$ & 560 & 731.14 & 744.17 & 23.61 & 4817.60 \\
\hline $\begin{array}{l}\text { Rational expectations of } \\
\text { housing sales volume }\end{array}$ & $i r_{i t}$ & 560 & 797.01 & 770.95 & 23.61 & 5100.40 \\
\hline Per capita GDP & $g d p_{i t}$ & 560 & 4953.52 & 5518.01 & 464.90 & $48,198.19$ \\
\hline Urban population (million) & $p e o_{i t}$ & 560 & 711.78 & 556.35 & 54.38 & 3375.00 \\
\hline $\begin{array}{l}\text { Per capita disposable } \\
\text { income of residents }\end{array}$ & $i n_{i t}$ & 560 & $17,002.01$ & 9583.31 & 4765.00 & $48,672.00$ \\
\hline $\begin{array}{l}\text { Per capita fiscal } \\
\text { expenditure }\end{array}$ & $f_{i t}$ & 560 & 4892.79 & 6994.36 & 0.00 & $65,245.18$ \\
\hline Interest rate level (\%) & $r_{i t}$ & 560 & 5.88 & 0.49 & 5.15 & 7.26 \\
\hline
\end{tabular}




\subsection{Unit Root Test}

To prevent spurious regression, a unit root test was performed on each variable using the LLC and IPS methods. The test results are listed in Table 3.

Table 3. Results of the unit root test.

\begin{tabular}{ccccc}
\hline \multirow{2}{*}{ Variable } & \multicolumn{2}{c}{ Original Sequence } & \multicolumn{2}{c}{ First-Order Difference Sequence } \\
\cline { 2 - 5 } & LLC Test & IPS Test & LLC Test & IPS Test \\
\hline $\ln h p_{i t}$ & $-11.91^{* * *}(0.00)$ & $-3.43^{* * *}(0.00)$ & $-19.25^{* * *}(0.00)$ & $-8.62^{* * *}(0.00)$ \\
\hline $\ln e s_{i t}$ & $-11.90^{* * *}(0.00)$ & $-2.99^{* * *}(0.00)$ & $-18.57^{* * *}(0.00)$ & $-7.91^{* * *}(0.00)$ \\
\hline $\ln e r_{i t}$ & $-12.03^{* * *}(0.00)$ & $-3.71^{* * *}(0.00)$ & $-18.34^{* * *}(0.00)$ & $-7.72^{* * *}(0.00)$ \\
\hline $\ln h q_{i t}$ & $-3.19^{* * *}(0.00)$ & $-1.43^{*}(0.07)$ & $-12.24^{* * *}(0.00)$ & $-11.75^{* * *}(0.00)$ \\
\hline $\ln i s_{i t}$ & $-2.07^{* * *}(0.01)$ & $-1.74^{* *}(0.04)$ & $-10.20^{* * *}(0.00)$ & $-13.13^{* * *}(0.00)$ \\
\hline $\ln i r_{i t}$ & $-2.53^{* * *}(0.00)$ & $-3.10^{* * *}(0.00)$ & $-8.82^{* * *}(0.00)$ & $-10.30^{* * *}(0.00)$ \\
\hline $\ln g d p_{i t}$ & $-8.19^{* * *}(0.00)$ & $-1.57(0.94)$ & $-20.18^{* * *}(0.00)$ & $-9.83^{* * *}(0.00)$ \\
\hline $\ln p e o_{i t}$ & $-7.56^{* *}(0.02)$ & $1.81^{* *}(0.96)$ & $-24.94^{* * *}(0.00)$ & $-13.45^{* * *}(0.00)$ \\
\hline $\ln i n_{i t}$ & $-10.85^{* * *}(0.00)$ & $-0.58^{* * 0.28)}$ & $-15.50^{* * *}(0.00)$ & $-5.54^{* * *}(0.00)$ \\
\hline $\ln f_{i t}$ & $-10.01^{* * *}(0.00)$ & $-1.85^{* *}(0.03)$ & $-23.48^{* * *}(0.00)$ & $-10.69^{* * *}(0.00)$ \\
\hline$r_{i t}$ & $-17.32^{* *}(0.01)$ & $-7.07^{* * *}(0.00)$ & $-31.50^{* * *}(0.00)$ & $-18.67^{* * *}(0.00)$ \\
\hline
\end{tabular}

Note: The data contained in brackets are $p$ values; ${ }^{* * *},{ }^{* *}$, and ${ }^{*}$ mean that original assumptions with unit roots are rejected respectively at $1 \%, 5 \%$, and $10 \%$ significance levels; LLC test values are adjusted $t$ values, used to check whether there are identical unit roots; IPS test values are $\mathrm{W}(\mathrm{t}-\mathrm{bar})$ values, used to check whether there are different unit roots.

The results of the LLC test show that the level values and the first-order difference values of the variables are all significant at different statistical levels (Table 3). The results of the IPS test show that the level values of $\ln g d p_{i t}$ (logarithm of per capita GDP), $\ln p e o_{i t}$ (logarithm of urban population), and $\ln i n_{i t}$ (logarithm of per capita disposable income) are not significant. However, the first-order difference values of these variables are significant at the $1 \%$ statistical level, along with the values of other variables. Therefore, the results of the unit root test show that all the variables meet the requirements for model estimation and can be used for empirical analysis.

\subsection{Selection of Estimation Method}

The system GMM method is an extension of the differential GMM method [41-43]. System-GMM can control the endogeneity problem of dynamic panel equations based on the information of both the level change and the differential change of variables, and yield unbiased, valid results. Due to the good properties of the GMM method, many studies have used this as an estimation tool [44-46]. The dynamic System-GMM is used for model estimation in this study.

\subsection{Analysis of Regression Results}

4.6.1. Dynamic GMM Analysis for the Effects of Expectations and Economic Fundamentals on Housing Prices

Using the System-GMM method, Equation (19) is estimated. The results of estimation are described in Table 4. The AR (1) and AR (2) statistics of each model show that there is no second-order serial correlation between model residues. The Sargan statistics of each model show that the over-identification of instrumental variables does not exist in these models, proving that the selected instrumental variables are reasonable. 
Table 4. Dynamic GMM estimation results on the effects of expectations and economic fundamentals on housing prices.

\begin{tabular}{ccccc}
\hline Variable & \multicolumn{2}{c}{ Adaptive Expectation } & \multicolumn{2}{c}{ Rational Expectation } \\
\hline $\ln e s_{i t} / \ln e r_{i t}$ & $0.66^{* * *}(26.10)$ & $0.68^{* * *}(26.38)$ & $0.59^{* * *}(18.73)$ & $0.62^{* * *}(21.32)$ \\
$\ln g d p_{i t}$ & $0.20^{* * *}(6.09)$ & $0.23^{* * *}(11.52)$ & $0.04(0.89)$ & \\
$\ln p e o_{i t}$ & $0.17^{* * *}(3.97)$ & $0.16^{* * *}(6.02)$ & $0.08^{* * *}(2.70)$ & $0.05^{* * *}(3.79)$ \\
$\ln i n_{i t}$ & $0.01(0.15)$ & & $0.27^{* * *}(6.18)$ & $0.28^{* * *}(7.82)$ \\
$\ln f_{i t}$ & $0.02(1.16)$ & & $0.05^{* * *}(3.06)$ & $0.06^{* * *}(4.40)$ \\
$r_{i t}$ & $-0.02^{* * *}(-4.58)$ & $-0.02^{* * *}(-5.00)$ & $-0.01^{* * *}(-2.68)$ & $-0.01^{* * *}(-2.91)$ \\
$\begin{array}{c}\text { Constant term } \\
p \text { value of AR } \\
\quad(1) \text { test }\end{array}$ & $0.50^{* * *}(-4.01)$ & $-0.59^{* * *}(-3.59)$ & $-0.52^{* * *}(-3.11)$ & $-0.40^{* * *}(-3.42)$ \\
$p$ value of AR \\
$\quad(2)$ test
\end{tabular}

Note: The data contained in brackets are $\mathrm{z}$ values of parameters, and ${ }^{* * *}$ denotes the significance level of $1 \%$; AR (1) and AR (2) are respectively the $p$ values of the Arellano-Bond first-order and second-order serial correlation tests of residues; the Sargan test is used to test the over-identification constraints of instrumental variables.

Table 4 lists the regression results of the effect of price expectations and economic fundamentals on housing prices. Specifically, Columns (2) and (3) list the results of adaptive expectations, and Columns (4) and (5) list the results of rational expectations. Some explanatory variables in Columns (2) and (4) are not significant. After the non-significant explanatory variables are deleted, a System-GMM analysis is conducted to obtain the regression results in Columns (3) and (5), which are used as the basis for analysis of the regression results.

Column (3) of Table 4 indicates that when market participants have adaptive expectations with regard to housing prices, the expected rise in housing prices has a significant positive effect on current housing prices. More specifically, a 1\% rise in adaptive expectations regarding housing prices causes a $0.68 \%$ rise in current housing prices. Among economic fundamentals, per capita and urban population are significantly positively correlated with housing prices. The coefficient of elasticity of housing prices to per capita GDP is 0.23 , and the coefficient of elasticity of housing prices to the urban population is 0.16 . Loan interest rate is significantly negatively correlated with housing prices at the $1 \%$ statistical level. A $1 \%$ rise in the loan interest rate causes a $0.02 \%$ decline in housing prices. Column (5) of Table 4 shows that when market participants have rational expectations on housing prices, a $1 \%$ rise in rational expectations on housing prices causes a $0.62 \%$ rise in the current housing prices, proving the significant positive effect of rational expectations on housing prices. A $1 \%$ rise in per capita disposable income, per capita fiscal expenditure, and urban population respectively causes an increase of $0.28 \%, 0.06 \%$, and $0.06 \%$ in current housing prices; a $1 \%$ rise in the loan interest rate causes a $0.01 \%$ decline in current housing prices.

4.6.2. Dynamic GMM Analysis for the Effect of Expectations and Economic Fundamentals on Housing Sales Volume

In addition to the effect of expectations on residential housing prices, this study also explored the effects of expectations and real demand on the housing sales volume. Model (20) was estimated using the dynamic GMM method (as described in Table 5).

Column (3) of Table 5 shows that when market participants have adaptive expectations of housing prices, the expected rise in housing sales volume has a positive effect on current housing prices, but the regression coefficient is not high. More specifically, a $1 \%$ rise in adaptive expectations with regard to housing sales volume causes a $0.06 \%$ rise in the current housing sales volume. Among economic fundamentals, per capita GDP, urban population, and per capita fiscal expenditure are all significantly positively correlated with the housing sales volume; their coefficients of elasticity are $0.38,0.88$, and 0.26 , respectively. Among economic fundamentals, the coefficient of regression of only the loan interest 
rate is negative. A $1 \%$ rise in the loan interest rate causes a $0.20 \%$ decline in the housing sales volume. Column (5) of Table 5 shows that when market participants have rational expectations of the housing sales volume, a $1 \%$ rise in these expectations causes a $0.09 \%$ rise in the current housing sales volume. A 1\% rise in per capita GDP, urban population, and per capita fiscal expenditure respectively causes an increase of $0.30 \%, 0.62 \%$, and $0.36 \%$ in current housing sales volume; a $1 \%$ rise in the loan interest rate causes a $0.22 \%$ decline in the current housing sales volume.

Table 5. Dynamic GMM estimation results for the effects of expectations and economic fundamentals on housing sales volume.

\begin{tabular}{|c|c|c|c|c|}
\hline \multirow{2}{*}{$\frac{\text { Variable }}{\ln i s_{i t} / \ln i r_{i t}}$} & \multicolumn{2}{|c|}{ Adaptive Expectation } & \multicolumn{2}{|c|}{ Rational Expectation } \\
\hline & $0.07^{* * *}(5.12)$ & $0.06^{* * *}(5.07)$ & $0.09^{* * *}(4.38)$ & $0.09^{* * *}(5.10)$ \\
\hline $\ln g d p_{i t}$ & $0.38^{* * *}(4.78)$ & $0.38^{* * *}(5.53)$ & $0.31^{* * *}(1.96)$ & $0.30^{* * *}(3.79)$ \\
\hline $\ln p e o_{i t}$ & $0.87^{* * *}(5.80)$ & $0.88^{* * *}(15.40)$ & $0.73^{* * *}(5.95)$ & $0.62^{* * *}(17.27)$ \\
\hline $\ln i n_{i t}$ & $0.04(0.22)$ & & $-0.01(0.95)$ & \\
\hline $\ln f_{i t}$ & $0.26^{* * *}(3.97)$ & $0.28^{* * *}(5.21)$ & $0.35^{* * *}(6.05)$ & $0.36^{* * *}(6.27)$ \\
\hline$r_{i t}$ & $\begin{array}{l}-0.20 * * * \\
(-34.84)\end{array}$ & $\begin{array}{l}-0.20^{* * *} \\
(-20.97)\end{array}$ & $\begin{array}{l}-0.22 * * * \\
(-19.91)\end{array}$ & $\begin{array}{l}-0.22 * * * \\
(-28.77)\end{array}$ \\
\hline Constant term & $\begin{array}{l}-5.00 \\
* * *(-12.58)\end{array}$ & $\begin{array}{c}-4.82 \\
* * *(-20.97)\end{array}$ & $-3.71^{* * *}(-6.49)$ & $-3.09^{* * *}(-7.64)$ \\
\hline $\begin{array}{l}p \text { value of AR } \\
\text { (1) test }\end{array}$ & 0.30 & 0.30 & 0.30 & 0.30 \\
\hline $\begin{array}{l}p \text { value of AR } \\
\text { (2) test }\end{array}$ & 0.33 & 0.34 & 0.31 & 0.31 \\
\hline $\begin{array}{l}p \text { value of } \\
\text { Sargan test }\end{array}$ & 1.00 & 1.00 & 1.00 & 1.00 \\
\hline
\end{tabular}

Note: The data contained in brackets are $\mathrm{z}$ values of parameters, and ${ }^{* * *}$ denotes the significance level of $1 \%$; AR (1) and AR (2) are respectively the $p$ values of Arellano-Bond first-order and second-order serial correlation tests of residues; the Sargan test is used to test the over-identification constraints of instrumental variables.

4.6.3. Dynamic GMM Analysis for the Effects of Price and Sales Volume Expectations on Housing Prices

How will residential housing prices vary when market participants have rational expectations of both housing prices and housing sales volume? Table 6 provides an answer to the question raised in Model (21). Models 1-4 in Table 6 reveal the results of the dynamic GMM estimation when market participants have different combinations of expectations with regard to housing prices and sales volume.

Table 6 indicates the following: First, price expectations are still a critical factor that affect current housing prices, whereas sales volume expectations marginally affect current housing prices. Second, economic fundamentals still have a significant effect on housing prices; specifically, economic development level, population, disposable income, and local fiscal expenditure have a marginally positive correlation with housing prices, and loan interest rate is still negatively correlated with current housing prices. Third, in terms of the coefficients of influence of explanatory variables on housing prices, price expectations outweigh the aggregate of economic fundamentals. 
Table 6. Dynamic GMM estimation results for the effects of price and sales volume expectations on housing prices.

\begin{tabular}{|c|c|c|c|c|}
\hline Variable & Model 1 & Model 2 & Model 3 & Model 4 \\
\hline $\ln e s_{i t}$ & $0.67^{* * *}(22.65)$ & $0.67^{* * *}(21.11)$ & & \\
\hline $\ln e r_{i t}$ & & & $0.59^{* * *}(25.48)$ & $0.59 * * *(15.60)$ \\
\hline $\ln i s_{i t}$ & $0.02 * * *(3.77)$ & & $0.00(0.71)$ & \\
\hline $\ln i r_{i t}$ & & $-0.02(-1.33)$ & & $-0.02(-1.65)$ \\
\hline $\ln g d p_{i t}$ & $0.12^{* * *}(2.94)$ & $0.19^{* * *}(5.53)$ & $-0.13(-1.42)$ & $0.07 *(1.67)$ \\
\hline $\ln p e o_{i t}$ & $0.08 *(1.86)$ & $0.14^{* * *}(2.75)$ & $0.04(0.69)$ & $0.10^{* * *}(4.16)$ \\
\hline $\ln i n_{i t}$ & $0.07(1.09)$ & $-0.00(-0.07)$ & $0.38^{* * *}(4.47)$ & $0.26^{* * *}(5.83)$ \\
\hline $\ln f_{i t}$ & $0.04^{* *}(2.03)$ & $0.06^{* *}(2.22)$ & $0.12 * * *(3.50)$ & $0.04^{* * *}(2.47)$ \\
\hline$r_{i t}$ & $-0.02^{* * *}(-4.37)$ & $-0.01^{* *}(-2.23)$ & $-0.01^{* * *}(-2.39)$ & $-0.01 * *(-2.24)$ \\
\hline Constant term & $-0.01(-0.04)$ & $-0.29(-1.17)$ & $-0.13(-0.65)$ & $-0.69^{* * *}(-3.90)$ \\
\hline $\begin{array}{l}p \text { value of AR } \\
\text { (1) test }\end{array}$ & 0.00 & 0.00 & 0.00 & 0.00 \\
\hline $\begin{array}{l}p \text { value of AR } \\
\text { (2) test }\end{array}$ & 0.51 & 0.24 & 0.12 & 0.11 \\
\hline $\begin{array}{l}p \text { value of } \\
\text { Sargan test }\end{array}$ & 1.00 & 1.00 & 1.00 & 1.00 \\
\hline
\end{tabular}

Note: The data contained in brackets are $\mathrm{z}$ values of parameters, and ${ }^{* * *},{ }^{* *}$, and ${ }^{*}$ denote the significance levels of $1 \%, 5 \%$, and 10\%, respectively; AR (1) and AR (2) are respectively the $p$ values of the Arellano-Bond first-order and second-order serial correlation tests of residues; the Sargan test is used to test the over-identification constraints of instrumental variables.

\section{Conclusions and Suggestions}

Focusing on the rapid rise of China's housing prices in recent years, we built the cheap talk game models to examine the correlation between individual housing purchase decisions, market expectations, and economic fundamentals. Based on the panel data of 35 large and medium-sized Chinese cities, we conducted an empirical analysis using the dynamic panel GMM estimation method. Accordingly, we draw conclusions and offer the following suggestions: First, from the perspective of maximized social utility, housing prices should be congruent with economic fundamentals; however, when the whole of society expects housing prices to rise, individual buyers' herd behavior of chasing housing prices will cause an overall increase in these prices regardless of economic fundamentals. Second, individual housing purchase decisions are significantly affected by information disclosure. The more accurate and reliable the disclosed information on economic fundamentals is, the more likely individual buyers are to make purchase decisions according to such information, thus maximizing overall social utility. Third, price expectations are a non-negligible factor that affect housing prices. Price expectations, whether they are adaptive or rational, are critical factors that are significantly positively correlated with housing prices regardless of the market expectations with regard to only housing prices or housing sales volume. Price expectations outweigh the economic fundamentals indicative of real demand, implying that housing purchases contain investment attributes in China. Fourth, each economic fundamental has a certain effect on housing prices, implying that the rise in China's housing prices in recent years is somewhat underpinned by objective economic conditions. Compared with price expectations, economic fundamentals affect housing prices less significantly. This further proves that housing prices contain some bubbles that are driven by market expectations.

In recent years, in order to control rapidly rising housing prices, relevant Chinese government departments have introduced a series of housing price control policies such as restrictive prices for new homes and guideline prices for second homes; however, the impact of these planned economy-style housing price intervention mechanisms on the market has been enormous. For example, the guideline price for second-hand houses was introduced in Shenzhen on 8 February 2021, and the volume of second-hand house transactions dropped sharply after the policy was released, with 3027 units sold in May, falling further in June to 2575 units, which is more than $70 \%$ lower than the 10,594 units 
sold in the same period in 2020; this does not contribute to the healthy and sustainable development of the local second-hand house market. However, the mechanisms proposed in this paper for the accurate disclosure of economic fundamentals and the impact of house price expectations are more market-oriented government actions, and this paper also demonstrates the effectiveness of these market-oriented mechanisms on house prices, which can provide lessons for the relevant government departments in China in terms of real estate price control policies.

The main contributions of this paper are as follows: Firstly, the micro-level theoretical basis of the house price influence mechanism was extended by using the cheap talk game model, which is rarely used in the field of real estate research. Secondly, the impact of some statistically inaccessible variables, such as information bias, on the home purchase decision was explored through a simulation analysis of the house price cheap talk game model. Finally, this paper obtained the relationship between individual house purchase decisions and economic fundamentals and expected information by constructing a micro-level cheap talk game model of individual house buyers' decisions. Then, the macro data of 35 large and medium-sized cities in China were used to empirically verify whether the conclusions of the cheap talk game model hold. The two models were shown to be closely linked, a kind of unification of the micro-decision model and the macro-data test.

The limitations of this study lie in several areas, which could be potential directions for future research. First, the sample data are limited to 35 large and medium-sized cities in China between 2000 and 2014, and future studies can try to empirically test whether the house price cheap talk game model proposed in this paper holds in other cities and over a longer time span $[23,24]$. Second, micro data are not addressed in this study. Micro data collected through research or questionnaire methods can portray the relationship between homebuyers' decisions and expectations and economic fundamentals in more detail [29-31]. Third, this study did not consider the influence of some micro elements on home purchase decisions. Therefore, in future studies, in addition to economic fundamentals and expectations, more micro elements such as community environment, infrastructure, educational resources, and unexpected events can be included in the modeling and empirical process [15-19,35-37].

Author Contributions: Conceptualization, J.W. and B.P.; methodology, J.W. and Z.M.; software, J.W. and Z.M.; validation, J.W., B.P. and X.X.; formal analysis, J.W.; investigation, B.P.; resources, X.X.; data curation, X.X.; writing —original draft preparation, J.W. and Z.M.; writing-review and editing, J.W. and Z.M.; visualization, J.W.; supervision, B.P.; project administration, B.P.; funding acquisition, B.P. All authors have read and agreed to the published version of the manuscript.

Funding: This research was funded by the National Social Science Foundation of China, grant number 21BJL099 and the National Natural Science Foundation of China, grant number 71974192.

Institutional Review Board Statement: Not applicable.

Informed Consent Statement: Not applicable.

Data Availability Statement: Not applicable.

Conflicts of Interest: The authors declare no conflict of interest.

\section{References}

1. Levin, E.J.; Wright, R. Speculation in the housing market? Urban Stud. 1997, 34, 1419-1437. [CrossRef]

2. Malpezzi, S. A simple error correction model of house prices. J. Hous. Econ. 1999, 8, 27-62. [CrossRef]

3. Gan, Q.; Hill, R.J. Measuring housing affordability: Looking beyond the median. J. Hous. Econ. 2009, 18, 115-125. [CrossRef]

4. Hou, Y.Z. Housing price bubbles in Beijing and Shanghai? A multi-indicator analysis. Int. J. Hous. Mark. Anal. 2010,3 , 17-37. [CrossRef]

5. Glaeser, E.; Huang, W.; Ma, Y.; Shleifer, A. A real estate boom with Chinese characteristics. J. Econ. Perspect. 2017, $31,93-116$. [CrossRef]

6. Case, K.E.; Shiller, R.J. The efficiency of the market for singlefamily homes. Am. Econ. Rev. 1989, 79, $125-137$.

7. Zhang, H.; Huang, Y.; Yao, H. Heterogeneous expectation, beliefs evolution and house price volatility. Econ. Model. 2016, 53, 409-418. [CrossRef] 
8. Shiller, R.J. Alternative tests of rational expectations models: The case of the term structure. J. Econom. 1981, 16, 71-87. [CrossRef]

9. West, K.D. A specification test for speculative bubbles. Q. J. Econ. 1987, 102, 553-580. [CrossRef]

10. Glaeser, E.L.; Nathanson, C.G. An extrapolative model of house price dynamics. J. Financ. Econ. 2017, 126, 147-170. [CrossRef]

11. Stefani, A.D. House price history, biased expectations, and credit cycles: The role of housing investors. Real Estate Econ. 2020, 49 , 1238-1266. [CrossRef]

12. Patrick, B.; Lanier, B.; Krainer, J. House prices and consumer welfare. J. Urban Econ. 2005, 58, 474-487.

13. Su, Z.; Huang, J.; Lin, A.J. House price expectations, mortgages, and subjective well-being in urban China. J. Consum. Aff. 2020, 10, 12334. [CrossRef]

14. Eh, A.; Psb, C. Heterogeneity in households' expectations of housing prices: Evidence from micro data. J. Hous. Econ. 2020, 50, 101731.

15. Kousky, C. Learning from extreme events: Risk perceptions after the flood. Land Econ. 2010, 86, 395-422. [CrossRef]

16. Votsis, A.; Perrels, A. Housing prices and the public disclosure of flood risk: A difffference-in-difffferences analysis in Finland. J. Real Estate Financ. Econ. 2016, 53, 450-471. [CrossRef]

17. Hansen, J.L.; Benson, E.D.; Hagen, D.A. Environmental hazards and residential property values: Evidence from a major pipeline event. Land Econ. 2006, 82, 529-541. [CrossRef]

18. Deng, G.; Gan, L.; Hernandez, M.A. Do natural disasters cause an excessive fear of heights? Evidence from the Wenchuan earthquake. J. Urban Econ. 2015, 90, 79-89. [CrossRef]

19. Wong, G. Has SARS infected the property market? Evidence from Hong Kong. J. Urban Econ. 2008, 63, 74-95. [CrossRef]

20. Fair, R.C. Disequilibrium in housing models: Discussion. J. Financ. 2012, 27, 207-221. [CrossRef]

21. Feng, Q.; Wu, G.L. Bubble or riddle? An asset-pricing approach evaluation on China's housing market. Econ. Model. 2015, 46, 376-383. [CrossRef]

22. Cuestas, J.C. House prices and capital inflows in Spain during the boom: Evidence from a cointegrated var and a structural bayesian var. J. Hous. Econ. 2017, 37, 22-28. [CrossRef]

23. Steger, T.; Knoll, K.; Schularick, M. No price like home: Global house prices, 1870-2012. Am. Econ. Rev. 2017, 107, 331-353.

24. Tsai, I.C. House price convergence in Euro zone and non-Euro zone countries. Econ. Syst. 2018, 42, 269-281. [CrossRef]

25. Singh, B.; Nadkarni, A.R. Role of credit and monetary policy in determining asset prices: Evidence from emerging market economies. N. Am. Econ. Financ. 2018, 51, 100874. [CrossRef]

26. Christiansen, C.; Eriksen, J.N.; Moller, S.V. Negative house price co-movements and US recessions. Reg. Sci. Urban Econ. 2019, 77, 382-394. [CrossRef]

27. Hirota, S.; Huber, J.; Stockl, T.; Sunder, S. Speculation, money supply and price indeterminacy in financial markets: An experimental study. J. Econ. Behav. Organ. 2020. [CrossRef]

28. Yeap, G.P.; Lean, H.H. Supply elasticity of new housing supply in Malaysia: An analysis across housing sub-markets. Econ. Bulle. 2020, 40, 807-820.

29. Li, R.Y.M. Generation X and Y's demand for homeownership in Hong Kong. Pac. Rim Prop. Res. J. 2015, 21, 15-36. [CrossRef]

30. Wilhelmsson, M. Energy performance certificates and its capitalization in housing values in Sweden. Sustainability 2019, $11,6101$. [CrossRef]

31. Li, R.Y.M.; Li, H. Have housing prices gone with the smelly wind? Big data analysis on landfill in Hong Kong. Sustainability 2018, 10, 304. [CrossRef]

32. Cho, S.H.; Roberts, R.K.; Kim, S.G. Negative externalities on property values resulting from water impairment: The case of the Pigeon River Watershed. Ecol. Econ. 2011, 70, 2390-2399. [CrossRef]

33. Giudice, D.V.; Paola, D.P. The effects of noise pollution produced by road traffific of Naples Beltway on residential real estate values. Appl. Mech. Mater. 2014, 587-589, 2176-2182. [CrossRef]

34. Brandt, S.; Maennig, W. Road noise exposure and residential property prices: Evidence from Hamburg. Transp. Res. Part D Transp. Environ. 2011, 16, 23-30. [CrossRef]

35. Xia, Z.; Hao, L.; Chen, Y. Assessing neighborhood walkability based on usage characteristics of amenities under Chinese metropolises context. Sustainability 2018, 10, 3879. [CrossRef]

36. Kim, E.J.; Kim, H. Neighborhood walkability and housing prices: A correlation study. Sustainability 2020, 12, 593. [CrossRef]

37. Abdelhalim, M.; Dubé, J.; Devaux, N. The spatial and temporal decomposition of the effect of floods on single-family house prices: A Laval, Canada case study. Sustainability 2021, 13, 5088. [CrossRef]

38. Crawford, V.P.; Sobel, J. Strategic information transmission. Econometrica 1982, 50, 1431-1451. [CrossRef]

39. Battaglini, M.; Benabou, R.J.; Tirole, J. Self-Control in Peer Groups; Institut d'Économie Industrielle: Toulouse, France, 2003; pp. 17-56.

40. Levy, G.; Razin, R. On the limits of communication in multidimensional cheap talk: A comment. Econometrica 2007, 75, 885-893. [CrossRef]

41. Arellano, M.; Bond, S. Some tests of specifification for panel data: Monte Carlo evidence and an application to employment equations. Rev. Econ. Stud. 1991, 58, 277-297. [CrossRef]

42. Arellano, M.; Bover, O. Another look at the instrumental variable estimation of error-components models. J. Econ. 1995, 68, 29-51. [CrossRef] 
43. Blundell, R.; Bond, S. Initial conditions and moment restrictions in dynamic panel data models. J. Econ. 1998, 87, 115-143. [CrossRef]

44. Li, R.Y.M.; Chau, K.W.; Ho, D. Dynamic panel analysis of construction accidents in Hong Kong. Asian J. Law Econ. 2017, 8, 2016-2022. [CrossRef]

45. Jiwattanakulpaisarn, P.; Noland, R.B.; Graham, D.J.; Polak, J.W. Highway infrastructure investment and county employment growth: A dynamic panel regression analysis. J. Reg. Sci. 2009, 49, 263-286. [CrossRef]

46. Ke, X.; Lin, J.Y.; Fu, C.; Wang, Y. Transport infrastructure development and economic growth in China: Recent evidence from dynamic panel system-gmm analysis. Sustainability 2020, 12, 5618. [CrossRef]

47. Galí, J.; Gertler, M. Inflation dynamics: A structural econometric approach. J. Monet. Econ. 1999, 44, 195-222. [CrossRef]

48. Malpezzi, S.; Wachter, S.M. The role of speculation in real estate cycles. J. Real Estate Lit. 2005, 13, 143-164. [CrossRef] 